\title{
Effects of Hypocalcemic Vitamin D Analogs in the Expression of DNA Damage Induced in Minilungs from Hescs: Implications for Lung Fibrosis
}

\section{Esmeralda Magro-Lopez}

Carlos III Health Institute: Instituto de Salud Carlos III

Irene Chamorro-Herrero

Carlos III Health Institute: Instituto de Salud Carlos III

Alberto Zambrano ( $\square$ azambra@isciii.es )

Instituto de Salud Carlos III Campus de Majadahonda https://orcid.org/0000-0001-5677-2999

\section{Research}

Keywords: human pluripotent stem cells, hESCs, minilungs, vitamin D; vitamin D analogs, paricalcitol, calcipotriol, lung fibrosis.

Posted Date: November 11th, 2021

DOI: https://doi.org/10.21203/rs.3.rs-1030901/v1

License: (c) (i) This work is licensed under a Creative Commons Attribution 4.0 International License. Read Full License 


\section{Abstract}

\section{Background}

In our previous work, we evaluated the therapeutic effects of $1 a, 25$-Dihydroxyvitamin $D_{3}$, the biologically active form of vitamin $D$, in the context of bleomycin-induced lung fibrosis. Contrary to the expected, vitamin D supplementation increased DNA damage expression and cellular senescence in alveolar epithelial type II cells and aggravated the overall lung pathology induced in mice by bleomycin. These effects were probably due to an alteration of the cellular DNA double-strand breaks repair capability. In the present work we have evaluated the effects of two hypocalcemic vitamin $D$ analogs (calcipotriol and paricalcitol) in the expression of DNA damage in the context of minilungs derived from human embryonic stem cells and in the cell line A549.

\section{Results}

As in the case of the cell line A549, bleomycin can induce DNA damage in the generated minilungs enriched in alveolar cells. The results indicate that, in contrast to vitamin $D$, the treatment of the minilungs with the hypocalcemic analogs reduce significantly the bulk of DNA damage expression in both bidimensional arrays of epithelial cells (2D minilungs) and lung bud organoids (3D minilungs). The initial evaluation of a battery of commercially available vitamin $D$ analogs shows a significant reduction in A549 cells of gH2AFX expression levels, a marker of DNA damage, cell senescence and aging.

\section{Conclusions}

The treatments based in hypocalcemic vitamin D analogs might be used to reduce the bulk of DNA damage and eventually the subsequent cell senescence expression that underlie lung conditions as those that can evolve with fibrosis.

\section{Background}

DNA damage and cellular senescence underlie the physiopathology associated to idiopathic pulmonary fibrosis (IPF) and other chronic conditions that can evolve with fibrosis. IPF is a form of progressive interstitial pneumonia of unknown etiology with an estimated survival of 3-4 years (1). IPF pathogenesis is the consequence of an excessive matrix deposition leading to tissue scarring and irreversible organ injury probably due to a persistent input of damage and tissue repair response. It has been reported that cellular senescence is implicated in the tissue repair program and its occurrence in IPF, unfortunately, has a detrimental role in contrast to other fibrogenic conditions (2) (3) (4). Vitamin D and its analogs have been proved to be active in the regulation of fibrosis that characterizes multiple chronic diseases including pulmonary fibrosis (5) (6) (7) (8). For instance, the preventive use preventive of vitamin D supplementation was associated to a general improvement of the lung fibrosis symptomatology induced in mice probably due to its anti-inflammatory effects (8) (9). However, as we have reported in our previous work, the "therapeutic" treatment of mice having bleomycin-induced fibrosis seemed to worsen the 
pathology: the mice treated with vitamin D showed increased architectural distortion, subpleural scarring and more areas of aberrant reepithelization compared to controls. These areas were defined by the accumulation of alveolar epithelial type II (ATII) cells harboring high levels of DNA damage in the form of double strand breaks (DSBs). DSBs were also observed in cells throughout respiratory bronchioles or immersed in alveolar fields. The bulk of DNA damage was preferably associated to epithelial cells; fibroblasts, however seemed to be more resistant to DNA damage than epithelial cells (10). Senescence can be induced prematurely as a result of a persistent DNA damage response (DDR) secondary to oxidative stress that induces double-strand breaks DSBs (11). Indeed, DSBs are potent inducers of cell arrest and a typical hallmark of cell senescence (12). Our results also showed significant greater levels of DSBs and cell senescence in epithelial cells than in fibroblasts and were consistent with the central hypothesis underlying IPF indicating that epithelial injury and impaired regeneration activate fibroblasts and that cellular senescence induced by persistent epithelial damage may be the origin of aberrant epithelial regeneration and the promotion of fibrosis (13) (14) (15) (16).

In the present study we have evaluated various vitamin D analogs in the context of DNA damage induced by sublethal doses of bleomycin. A huge amount of vitamin $D$ analogs have been synthesized during the years and their clinical use for secondary hyperparathyroidism, osteoporosis or psoriasis has been approved for many of them (17) (18). The potent effect of vitamin D on intestinal calcium and phosphorus absorption and bone mineral mobilization often leading to the development of hypercalcemia and hyperphosphatemia has precluded its therapeutic use for many conditions. The ideal analog would retain vitamin $D$ receptor binding capacities and have minimal effects on calcium and phosphorus metabolism. Our working hypothesis is that hypocalcemic vitamin $D$ analogs could show a lower incidence in the expression of DNA damage upon a bleomycin insult than the active form of vitamin D.

\section{Results}

We have tested our postulated hypothesis in the cell line A549, an immortalized counterpart of ATII cells, in 2D minilungs (lung and alveolar differentiated cells from $\mathrm{hESC}$ arranged in bidimensional cultures) and in 3D minilungs from hESCs (human lung bud organoids embedded in Matrigel ${ }^{\mathrm{TM}}$ sandwiches). Lung organoids generated from hESCs have enormous advantages over cell lines or simple primary cultures as they offer an unlimited availability of primary cells, they show the complete lung epithelial spectrum and emulate structural and functional features of the original organ.

The exposure of A549 cells to a sublethal bleomycin shock $(12 \mu \mathrm{g} / \mathrm{mL}$ for $6 \mathrm{~h})$ induces the expression of DNA damage (DD) foci containing TP53BP1, a reliable marker of DSBs (19) (20) (21) (22) (23). These conditions allow the accurate quantification of DSBs. DD foci are rapidly visualized as discrete foci in a pan-nuclear pattern (Figure 1A). As previously reported (10), the exposure of A549 cells to vitamin D, in the presence of bleomycin, increased the levels of DD foci, both the percentage of damaged cells and the levels of severely damaged cells harboring more than 20 DD foci per nucleus (Figure 1B-D) (n=3; >150 cells were analyzed; $P<0,001$ ). However, the two hypocalcemic vitamin $D$ analogs tested (paricalcitol and 
calcipotriol) were able to drastically reduce the bulk of DD expression compared to vitamin $D$ in the presence of bleomycin (Figure 2C-D; $n=3 ;>150$ cells were analyzed; ANOVA $P<0,001$ ). Figure 2A-B shows that the treatment of $A 549$ cells with vitamin D or its analogs, in the absence of bleomycin, did not alter the low basal level of damage of the cell population as previous described for vitamin $D(10)(n=3 ;>150$ cells were analyzed; ANOVA $\mathrm{P}<0,001)$. In order to reproduce these results in much more reliable models of lung structure and function we generated minilungs from hESCs as previously described (24) (25). By one hand we generated lung airway and epithelial cells arranged in bidimensional cultures (2D minilungs) from the hESC line AND-2 as previously described (24). Briefly, good hESCs colonies are grown along inactivated MEFs (iMEFs), picked-up and passaged to new plates with MEFsi in order to accumulate material for lung differentiation. Figure 3A shows the expression of pluripotency marker SOX-2 in a good AND-2 colony and representative micrograph at various times of the differentiation process: embryoid bodies (EBs), anterior foregut endoderm (AFE), cultures at day 23 (lung progenitors) and at day 60 (differentiated lung airway and alveolar cells). Cultures from day 50 onwards show the expression of representative markers of lung airway and alveolar cells illustrating the heterogeneity in cell shape including the presence of flat cells with a crescent shape morphology, and granular and roughly cuboidalshaped cells, likely corresponding to ATI and ATII cells, respectively (Figure 3A; d60). Although from day 50 they can be considered mature we the cultures were used for the desired experimentation from day 60 on. Figure 3B shows a RT-qPCR result illustrating the complexity of these cultures ( $n=3 ;>4$ organoids per experimental replicate were used). As previously described by us and others (24) (25) (26) (27) (28), the differentiation protocol applied yields cultures enriched in alveolar epithelial cells (ATI and ATII cells). By other hand, the generation of 3D minilungs implies the formation of nascent organoids in suspension at certain time of the protocol (see material \& methods for details) (Figure 3C) and their final embedding in Matrigel ${ }^{\mathrm{TM}}$ sandwiches to reach the desirable state of differentiation characterized by the presence of lung buds more or less branched [lung buds organoids (LBOs)] as previously described (25) (28) (Figure 3D). Figure 3E shows representative micrographs of histochemical analysis (H\&E staining) and immunohistochemical analysis with surfactant antibodies performed on LBOs sections. In order to analyze the expression of DNA damage and the effect of vitamin $D$ and its analogs, $2 D$ minilungs were treated with $12.5 \mu \mathrm{g} / \mathrm{mL}$ of bleomycin for $72 \mathrm{~h}$ due to the heterogeneity and density of these cultures. All the cell types of these complex cultures seemed to be affected equally by the bleomycin treatment. As in the case of A549 cells, neither vitamin D nor its hypocalcemic analogs altered significantly the basal levels of DD in the absence of bleomycin (Figure 4A-B) $(n=3 ;>150$ cells were analyzed; ANOVA $P<0,001)$. As expected, the exposure of these cultures to bleomycin and vitamin $D$ increased the levels of DD foci reached by bleomycin itself (Figure 4C-D). As in the case of A549 cells, the treatment with paricalcitol and calcipotriol not only did not they further increase the DD levels reached by bleomycin, but they seemed to reduce significantly the DD expression induced by bleomycin (Figure 4C-D, $(n=3$; $>4$ organoids per condition were used and $>150$ cells were analyzed; ANOVA $P<0,001)$. Equivalent assays were performed on 3D minilungs except the concentration of bleomycin used $(25 \mu \mathrm{g} / \mathrm{mL}$ instead of $12,5 \mu \mathrm{g} / \mathrm{mL})$ with the idea that enough bleomycin could reach the embedded material. As previously reported, lung buds minilungs are mainly constituted by ATII cells (28) (25). Although to a lesser extent we found similar results to those obtained in the case of $2 \mathrm{D}$ minilungs (Figure $4 \mathrm{E}-\mathrm{H})(\mathrm{n}=3 ;>4$ organoids per condition were 
used and >150 cells were analyzed; ANOVA P>0,05 (panels 4E-F) and ANOVA P<0,001 for data represented in panels 4G-H). Finally, we evaluate in A549 cells, a continuous cell line counterpart of ATII cells, the expression of gH2AFX marker which is a reliable marker of DD, cell senescence and aging, as previously described (22) (29) (22). Figure 4 I shows the significant increase in gH2AFX expression levels in the presence of bleomycin and vitamin $D$ compared to controls and the drastic reduction induced by paricalcitol. Equivalent assays were performed using a battery of commercially available less hypercalcemic vitamin D analogs including 22-oxacalcitriol, tacalcitol and vitamin D2. All the vitamin D analogs seemed not to further increase the expression levels of gH2AFX reached in bleomycin treated cells (Figure 4J). Moreover, in the case of paricalcitol, a significant reduction in the expression of gH2AFX compared to bleomycin treated cells is observed.

\section{Discussion}

The generation of human minilungs which share the structural features and some extent of the functionality of the native organ may serve as system model to emulate the DNA damage inflicted during the course of fibrogenic conditions such as IPF. Currently, the more efficient protocols to generate airway and alveolar epithelial cells from the direct differentiation of hPSCs are biased to the production of alveolar cells (28) (26) (25). Bleomycin seems to inflict DNA damage in the form of DSBs in all the epithelial cells equally, even when the cell organization is the form of lung buds embedded in Matrigel ${ }^{\mathrm{TM}}$ sandwiches. Altogether the initial results presented here suggest that less hypercalcemic analogs don't show the deleterious effects observed by vitamin $D$ treatment in the presence of bleomycin and could be an alternative to vitamin $\mathrm{D}$ supplementation. In addition, the treatment with this kind of vitamin $\mathrm{D}$ analogs could be tested as efficient agents to reduce the bulk of DD expression underlying multiple diseases that can evolve with DNA damage, fibrosis and aging such as IPF and other lung interstitial conditions.

\section{Material And Methods}

\section{Cell culture}

Alveolar epithelial cells type II (A549, ATCC) were maintained in DMEM medium supplemented with $10 \%$ FBS (Sigma), $2 \mathrm{mM}$ glutamine and $100 \mathrm{U} / \mathrm{mL}$ of penicillin and streptomycin (Lonza). We used the active form of vitamin D (1a,25-Dihydroxyvitamin $D_{3}$ or calcitriol) (cat.\#D1530; Sigma-Aldrich; Vitamin D stock was $10 \mu \mathrm{M}$ in ethanol) and the following vitamin D analogs (stocks were $50 \mu \mathrm{M}$ in ethanol): calcipotriol (cat.\#203537; Santa Cruz Biotechnology), paricalcitol (cat.\#477938; Santa Cruz Biotechnology), tacalcitol (cat.\#sc-361371a; Santa Cruz Biotechnology), 22-0xacalcitriol (cat.\#sc-361076; Santa Cruz Biotechnology) and vitamin D2 (cat.\#sc- sc-205988; Santa Cruz Biotechnology). Treatments were performed in cells maintained in DMEM supplemented with $10 \%$ hormone-depleted serum. This serum was prepared by using the anion exchange resin AGR1-X8 from BIO-RAD (cat.\#1401441) as previously described (22). Bleomycin sulfate (cat.\# CAYM13877-50) was purchased to VWR (Bleomycin stock: 50 $\mathrm{mM}$ in PBS). 


\section{Maintenance of hESCs}

The hESCs line AND-2 was obtained from the "Biobanco de células madre de Granada" (ISCIII, Spain); passages 26-40. Mouse embryonic fibroblasts (MEFs) were obtained at 13.5 days post-coitum from C57BL/ 6 mice as described previously (22). MEFs were mitotically inactivated by an overnight treatment with $2 \mu \mathrm{g} / \mathrm{mL}$ of mitomycin C (cat.\#M4287; Sigma-Aldrich) and plated at a density of approximately 16000 cells $/ \mathrm{cm}^{2}$. hESCs were cultured along with MEFs under standard conditions (http://www.stembook.org). The maintenance medium was composed of KO-DMEM (cat.\#10829-018 Gibco; Life Technologies), 20\% KO serum replacement (cat.\#10828010 Gibco; Life Technologies), 0,1 mM ß-mercaptoethanol (cat.\#21985-023 Gibco; Life Technologies), 2 mM Glutamax (cat.\#35050-061,Gibco; Life Technologies), nonessential aminoacids (cat.\#11140-050 Gibco; Life Technologies and primocin (cat.\#12I05MM; InvivoGen). The medium was filtered by using 0,22- $\mu$ pore filter systems (cat.\#431097; Corning); $10 \mathrm{ng} / \mathrm{mL}$ recombinant human basic Fibroblast Growth Factor (hbFGF) (cat.\#PHG6015; Invitrogen) and $10 \mu \mathrm{M}$ Y-27632 (cat.\#1254; Tocris R\&D Systems) were added before use. The medium was changed in a daily basis and cells were passaged either by enzymatic (collagenase IV method) (collagenase IV: cat.\#11140050; Gibco; Life Technologies) or mechanical procedures (http://stembook.org). Cells were maintained in an undifferentiated state in a $5 \% \mathrm{CO}_{2} /$ air environment. The differentiation process was carried-out in a $5 \% \mathrm{CO}_{2} / 5 \% \mathrm{O}_{2} / 95 \% \mathrm{~N}_{2}$ environment [Galaxy $48 \mathrm{R}$ incubator (New Brunswick)], unless otherwise indicated.

\section{Primitive streak formation and induction of definitive endoderm (DE)}

Induction of endoderm was performed as previously described (Magro-Lopez et al., 2018, 2017). Primitive streak formation (day $0 ; 24 \mathrm{~h}$ ) and endoderm induction (days 1-4) were performed in serum-free differentiation (SFD) medium. SFD medium was composed of a mix of IMDM:F12 (3:1) media (cats.\#B12-722F and 10-080 CVR; Corning), supplemented with N2 (cat.\#17502-048, Gibco; Life Technologies), B27 (cat.\#17504-044, Gibco; Life Technologies), 2 mM Glutamax (cat.\#35050-061 Gibco; Life Technologies), $1 \%$ penicillin-streptomycin (DE17-602E; Lonza), and $0.05 \%$ bovine serum albumin (BSA) (cat.\#A7906; Sigma-Aldrich). The medium was filtered using a $0.22 \mu$-pore filter system (cat.\#431097; Corning); $50 \mu \mathrm{g} / \mathrm{mL}$ ascorbic acid (cat.\#A4554; SigmaAldrich) and $0.04 \mu \mathrm{L} / \mathrm{mL}$ monothioglycerol (stock >97\%) (cat.\#M6145; Sigma-Aldrich) were added before use. MEFs were depleted by passaging hESCs lines onto Matrigel ${ }^{\mathrm{TM}}$-coated (cat.\#354230; Life Technologies) plates for at least 48h. Cells were briefly trypsinized into small 3-10 cell clumps and the reaction was halted with stop medium [IMDM medium (BE12722F) supplemented with 50\% foetal bovine serum (F7524, SigmaAldrich), 2 mM Glutamax, 1\% penicillin-streptomycin and $30 \mathrm{ng} / \mathrm{mL}$ DNase I (cat.\#260913-10MU; Calbiochem)]. Cells were then centrifuged $5 \mathrm{~min}$ at $850 \mathrm{rpm}$ and washed carefully two times with an excess of SFD medium. To form embryoid bodies (EBs), the clumps were plated onto low-attachment 6well plates (cat.\#3471; Corning) and maintained in SFD medium in a $5 \% \mathrm{CO}_{2} / 5 \%$ 02/95\% $\mathrm{N}_{2}$ environment (Galaxy 48R incubator; New Brunswick). 
For primitive streak formation, $10 \mu \mathrm{M}$ Y-27632, $10 \mathrm{ng} / \mathrm{mL}$ Wnt3a (cat.\#5036-WN; R\&D Systems) and 3 $\mathrm{ng} / \mathrm{mL}$ human BMP4 (cat.\#314-BP; R\&D Systems) were used. EBs were collected, resuspended carefully in endoderm induction medium containing $10 \mu \mathrm{M} \mathrm{Y}-27632,0.5 \mathrm{ng} / \mathrm{mL}$ human BMP4, $2.5 \mathrm{ng} / \mathrm{mL} \mathrm{hbFGF}$, and $100 \mathrm{ng} / \mathrm{mL}$ human Activin (cat.\# 338-AC; R\&D Systems). Cells were fed after 36-48 h, depending on cell density, by removing half the old medium and adding half fresh medium.

\section{Induction of anterior foregut endoderm (AFE)}

AFE (days 4, 5 or 5) was induced as previously described (Magro-Lopez et al., 2018, 2017). EBs were dissociated into single cells with trypsin. Dissociated cells were transferred to a conical tube containing stop medium to neutralize trypsin. Cells were centrifuged for $5 \mathrm{~min}$ at $850 \mathrm{rpm}$, washed carefully twice with SFD medium and counted. For AFE induction, 25.000-30.000 cells $/ \mathrm{cm}^{2}$ were plated on fibronectincoated (F0895; Sigma-Aldrich) 12-well tissue culture plates in AFE induction medium 1 [SFD medium supplemented with $10 \mathrm{mM}$ SB-431542 (cat.\#1614; Tocris) and $100 \mathrm{ng} / \mathrm{mL}$ of NOGGIN (cat.\#6057; R\&D Systems). After 24h of incubation, the medium was aspirated and AFE induction medium 2 [SFD medium supplemented with $1 \mu \mathrm{M}$ IWP2 (cat.\#3533; Tocris) and $10 \mu \mathrm{M}$ of SB-431542] was added to the cultures. This process was carried out under hypoxic conditions only for bidimensional cultures.

\section{Lung progenitors induction and expansion}

Lung progenitor induction and expansion was carried out as previously described (Magro-Lopez et al., 2018 , 2017). On day 6,5-7, AFE cultures treated for 20 days with the ventralization medium consisting of SFD medium supplemented with $3 \mu \mathrm{M}$ CHIR99021 (cat.\#04; Tocris), $10 \mathrm{ng} / \mathrm{mL}$ human FGF10 (cat.\#345FG; R\&D Systems), $10 \mathrm{ng} / \mathrm{mL}$ human KGF (cat.\#251KG-010; R\&D Systems), $10 \mathrm{ng} / \mathrm{mL}$ human BMP4 (cat.\#314-BP; R\&D Systems), 10 ng/mL murine EGF (cat.\#2028-EG-200; R\&D Systems) and $50 \mathrm{nM}$ alltrans retinoic acid (cat.\#R2625; Sigma-Aldrich). Culture medium was changed every two days. At a time point between days 8 to 12 cultures were incubated under normoxic conditions. At day 16, cultures were briefly digested with trypsin in order to remove potential nonectodermal contaminating cells. Supernatant of this brief digestion containing single cells and small clumps were removed. The remaining cell clumps were replated onto fibronectin-coated MW12 plates at 1:3 dilutions in fresh medium after trypsin neutralization and careful washing. Plates were returned to the hypoxic conditions $\left(5 \% \mathrm{CO}_{2} / 5 \% \mathrm{O}_{2} / 95 \% \mathrm{~N}_{2}\right.$ environment).

\section{Lung and airway epithelial cells maturation}

At day 26 cultures were incubated with SFD medium supplemented with $3 \mu \mathrm{M}$ CHIR99021, $10 \mathrm{ng} / \mathrm{mL}$ human FGF10, 10 ng/mL human FGF10, 0,1 mM 8-bromocAMP (cat.\# B5386; Sigma-Aldrich), 0,1 mM IBMX (3,7-dihydro-1-methyl-3-(2methylpropyl)-1H-purine-2,6-dione; cat.\# I5879; Sigma-Aldrich)) and 60 nM dexamethasone (cat.\#D5902; Sigma-Aldrich). The medium was changed every two days and plates were maintained under conditions $\left(5 \% \mathrm{CO}_{2} / 5 \% \mathrm{O}_{2} / 95 \% \mathrm{~N}_{2}\right.$ environment). Cultures were carried further in these conditions until their experimental use at day 50 . Treatments were performed in minilungs maintained in day 26 medium as indicated in the corresponding experiments. 


\section{Formation of lung bud organoids}

In this case, the differentiation process was performed under normoxic conditions from the anteriorization stage on. At day 8, cells were briefly trypsinized into small 3-10 cell clumps and the reaction was halted with stop medium (IMDM medium (BE12-722F) supplemented with $50 \%$ fetal bovine serum (FBS; F7524; Sigma-Aldrich), 2 mM Glutamax, 1\% penicillin-streptomycin). Cells were then centrifuged for $5 \mathrm{~min}$ at $850 \mathrm{rpm}$ and washed carefully twice with an excess of SFD medium. The clumps were plated onto low-attachment six-well plates (cat.\#3471; Corning) in branching medium (SFD medium containing $3 \mu \mathrm{M}$ CHIR99021, $10 \mathrm{ng} / \mathrm{mL}$ FGF10, $10 \mathrm{ng} / \mathrm{mL}$ KGF, $10 \mathrm{ng} / \mathrm{mL}$ BMP4, $50 \mathrm{nM}$ all-trans retinoic acid). These three-dimensional clumps (nascent lung bud organoids) were incubated and fed every other day for approximately 20-25 days. After that, these nascent organoids were embedded into a Matrigel ${ }^{\mathrm{TM}}$ sandwich assembled on MW96 wells. $50 \mu \mathrm{L}$ of Matrigel ${ }^{\mathrm{TM}}$ was loaded on the MW96 well and allowed to gel. Nascent organoids were picked up with a wide mouth plastic Pasteur pipette, divided into MW96 wells containing $50 \%$ Matrigel $^{\mathrm{TM}}$, diluted in branching media and immediately transferred onto the first layer of Matrigel ${ }^{\mathrm{TM}}$. After solidification of this intermediate layer containing the nascent organoids, 50 $\mu \mathrm{LMatrigel}{ }^{\mathrm{TM}}$ was added on top. Finally, each sandwich containing various organoids was incubated with $50 \mu \mathrm{L}$ branching media. Medium was changed every 2-3 days. Growing branching structures were easily visualized under the microscope after 1 or 2 weeks. Treatments were performed in minilungs maintained in branching medium as indicated in the corresponding experiments.

\section{Indirect immunofluorescence of A549 cells and 2D minilungs}

Cells were seeded in 8-well chambers (cat.\#154,534; Thermofisher Scientific) at a density of 20.000 cells/well. The following day the cells were treated as indicated in the corresponding experiments. Immunofluorescence was performed as previously described (Zambrano et al., 2014). Basically, cells were fixed in $2 \%$ PFA in PBS for 10 min at RT and permeabilized with $0.1 \%$ Triton X-100 and $0.1 \%$ sodium citrate for $5 \mathrm{~min}$ at RT. Preparations were washed with PBS and washing solution (PBS/0.25\% BSA/0.1\% Tween 20), blocked for 30 min with blocking solution (washing solution $+2.5 \% \mathrm{BSA}$ ), and incubated overnight with antibodies against TP53BP1(1:500; sc-16565; Invitrogen). Preparations were then washed with washing solution and incubated with secondary antibodies conjugated with alexa fluor dyes (488, 546) from Life Technologies (cat.\#A-11029, cat.\#A-11035) for $1 \mathrm{~h}$ at RT. Nuclei were counterstained with DAPI, and samples were mounted with ProLong Diamond (cat.\#P36961; Life Technologies). Cell images were captured with a fluorescence microscopy (Zeiss Axio) equipped with a camera (AxiocamMRm) and AxioVision software. DNA damage foci were quantified by counting from $>150$ cells for each experimental condition. For $2 \mathrm{D}$ minilungs, the glass chamber slides were incubated overnight at $4^{\circ} \mathrm{C}$ with human fibronectin in order to plate the differentiated cells. Cultures from day 50 were digested with trypsin, neutralized with stop medium and washed with SFD medium. Approximately 40.000 differentiated epithelial cells per well were plated in the epithelial maturation medium. Cultures were maintained in normoxic conditions for one day before treatments.

\section{Indirect immunofluorescence of lung bud organoids}


Organoids were picked up from the MW96 wells, transferred into a well of a MW12 and fixed with 4\% paraformaldehyde (PFA) for $15 \mathrm{~min}$ at RT. After that, the organoids were washed three times with PBS for $10 \mathrm{~min}$ and incubated overnight at $4^{\circ} \mathrm{C}$ with $30 \%$ sucrose. The sucrose was exchanged for a solution of $7.5 \%$ gelatin $/ 15 \%$ sucrose and incubated for $15 \mathrm{~min}$ at $37^{\circ} \mathrm{C}$. The organoids were carefully transferred to cryomolds and progressively embedded in various layers of solidified $7.5 \%$ gelatin $/ 15 \%$ sucrose. These preparations were cut into 10- $\mu \mathrm{m}$ sections in a Leica CM3050 cryostat. The mounted sections were washed with PBS and permeabilized with PBS/1\% BSA/0.25\% Triton X-100 for 5 min at RT. After that, the sections were washed and blocked for $30 \mathrm{~min}$ at RT with blocking solution (PBS-BSA 1\%). The sections were incubated for $2 \mathrm{~h}$ with antibodies against TP53BP1 (1:500; sc-16565; Invitrogen) or the pro surfactant protein $\mathrm{C}$ (1:200; ab3785, Merck). Preparations were washed with washing solution and incubated with a secondary antibody conjugated with Alexa fluor dye (546) from Life Technologies (cat.\#A-11035) for $1 \mathrm{~h}$ at room temperature. Nuclei were counterstained with DAPI and samples were mounted with ProLong Diamond (cat.\#P36961; Life Technologies). Cell images were captured with a fluorescence microscopy (Zeiss Axio) equipped with a camera (AxiocamMRm) and AxioVision software. DNA damage foci were counted from $>150$ cells for each experimental condition.

\section{Analysis of proteins by western-blot}

Cell monolayers were washed with ice-cold PBS and lysed in triple-detergent lysis buffer [50 $\mathrm{mM}$ Tris- $\mathrm{HCl}$ $\mathrm{pH}$ 8.0, $150 \mathrm{mM} \mathrm{NaCl}, 0.02 \%$ sodium azide, $0.1 \%$ SDS, $1 \%$ NP-40, $0.5 \%$ sodium deoxycholate, $100 \mu \mathrm{g} / \mathrm{ml}$ PMSF, $2 \mu \mathrm{g} / \mathrm{ml}$ pepstatin, $2 \mu \mathrm{g} / \mathrm{ml}$ aprotinin, $2 \mu \mathrm{g} / \mathrm{ml}$ leupeptin, and phosphatase inhibitors cocktail 2 or 3 (cat.\#P5726, P0044, Sigma-Aldrich)]. SDS-PAGE and immunoblotting were performed under standard conditions. Basically, samples in Laemmli buffer ( $30 \mu \mathrm{g} / \mathrm{lane}$ ) were separated through $12 \%$ gels and transferred to nitrocellulose membranes for 90 min at RT in the presence of $20 \%$ methanol and $0,1 \%$ SDS. Membranes were blocked with 3\% BSA in PBS-Tween 0,05\% (PBST-BSA) and incubated $0 / \mathrm{N}$ at $4{ }^{\circ} \mathrm{C}$ with a YH2AFX antibody (cat.\#05-636, Millipore) diluted 1:1000 in PBST-BSA. Densitometry analysis of bands was performed by using Image $\mathrm{J}$ software (https://imageJ.nih.gov/)

\section{Quantitative real-time RT-PCR (RT-qPCR) of minilungs}

Total RNA was extracted using Trizol (cat.\#15596026; Ambion) following manufacturer's instructions. cDNA was generated using the High-Capacity cDNA kit (cat.\#4387406; Applied Biosystems). Real-time qPCR was performed by using the powerUpSYBR Green mix (cat.\#A25742) on the Quantstudio-3 system (Applied Biosystems) following manufacturer's instructions. Absolute quantification of each gene was obtained using a standard curve of serial diluted genomic DNA (cat.\#11807720, Roche) and normalized to housekeeping gene TBP (Tata Box Binding protein)

The genes analyzed and the sequences of the oligonucleotides employed in this study, were the following: TBP [Tata-Box Binding Protein; Forward: 5'-TGAGTTGCTCATACCGTGCTGCTA, Reverse: 5'CCCTCAAACCAACTTGTCAACAGC]; TP63 (Tumor Protein P63, marker of basal cells) [Forward: 5'CCTATAACACAGACCACGCGCAGA, Reverse: 5'-GTGATGGAGAGAGAGCATCGAAG]; MUCIN5AC (Mucin 5AC, marker of globet cells ) [Forward: 5'GCACCAACGACAGGAAGGATGAG, Reverse: 5'- 
CACGTTCCAGAGCCGGACAT]; SCGB1A1 (Secretoglobin Family1A Member1 or CC10, marker of clara cells) [Forward: 5'-TCATGGACACACCCTCCAGTTATGAG,

Reverse: 5'-TGAGCTTAATGATGCTTTCTCTGGGC]; PDPN (Podoplanin, marker of AT-I cells) [Forward: 5'AGGAGAGCAACAACTCAACGGGA, Reverse: 5'- TTCTGCCAGGACCCAGAGC]; AQP5 (Aquaporin 5, marker of AT-I cells) [Forward: 5'- GCCATCCTTTACTTCTACCTGCTC, Reverse: 5'-

GCTCATACGTGCCTTTGATGATGG]; SFTPA (Surfactant Protein A, marker of AT-II cells) [Forward: 5'GTGCGAAGTGAAGGACGTTTGTG, Reverse: 5'-TTTGAGACCATCTCTCCCGTCCC]; SFTPB (Surfactant Protein B, marker of AT-Il cells) [Forward: 5'-TCTGAGTGCCACCTCTGCATGT, Reverse: 5'TGGAGCATTGCCTGTGGTATGG]; SFTPC (Surfactant Protein C, marker of AT-II cells) [Forward: 5'CCTTCTTATCGTGGTGGTGGTGGT, Reverse: 5'-TCTCCGTGTGTTTCTGGCTCATGT]; SFTPD (Surfactant Protein D, marker of AT-II cells) [Forward: 5'-TGACTGATTCCAAGACAGAGGGCA, Reverse: 5'TCCACAAGCCCTGTCATTCCACTT]; FOXJ1 (Forkhead Box J1, marker of ciliated cells) [Forward: 5'GGCATAAGCGCAAACAGCCG, Reverse: 5'-TCGAAGATGGCCTCCCAGTCAAA]

\section{Statistical analysis}

Data were subjected to the Shapiro-Wilk test and D'Agostino and Pearson omnibus test to verify their normality. Statistical significance of data was determined by applying a two-tailed Student's t test or analysis of variance followed by the Newman-Keuls or Bonferroni post-tests for experiments with more than two experimental groups. $\mathrm{P}<0.05$ is considered significant. Significance of analysis of variance post-test or the Student's $t$ test is indicated in the figures as *, P< $0.05 ; * \star, P<0.01$; and $* \star \star, P<0.001$. Statistics were calculated with the Prism 7 software (GraphPad Software). The results presented in the figures are means $\pm S E M$. Experiments were repeated three times.

\section{Abbreviations}




\begin{tabular}{|c|c|}
\hline AFE & Anterior Foregut Endoderm \\
\hline ATI & Alveolar Type I Cells \\
\hline ATII & Alveolar Type II Cells \\
\hline$B M P 4$ & Bone Morphogenic Protein 4 \\
\hline BSA & Bovine serum albumin \\
\hline DD & DNA damage \\
\hline DD foci & DNA damage foci \\
\hline DSBs & DNA double-strand breaks \\
\hline EBs & Embryoid Bodies \\
\hline FBS & Foetal bovine serum \\
\hline FGF & Fibroblast Growth Factor \\
\hline FOXJ1 & Forkhead Box J1 \\
\hline$H 2 A F X$ & $\mathrm{H} 2 \mathrm{~A}$ histone family member $\mathrm{X}$ \\
\hline hbFGF & Human basic fibroblast growth factor \\
\hline hESCs & Human Embryonic Stem Cells \\
\hline hPSCs & Human Pluripotent Stem Cells \\
\hline IBMX & Isobutylmethylxanthine \\
\hline IPF & Idiopathic Pulmonary Fibrosis \\
\hline KGF & Keratinocyte growth factor \\
\hline LBOs & Lung bud organoids \\
\hline MEFs & Mouse Embryonic Fibroblasts \\
\hline MUCIN5AC & Mucin 5AC, Oligomeric Mucus/Gel-Forming \\
\hline PBS & Phosphate-buffered saline \\
\hline$P D P N$ & Podoplanin \\
\hline RT-qPCR & Quantitative Real-Time RT-PCR (Reverse Transcription Polymerase Chain Reaction) \\
\hline SCGB1A1 & Secretoglobin Family 1A Member 1; CC10 \\
\hline SEM & Standard error of the mean \\
\hline SFD & Serum-free differentiation \\
\hline SFTPA & SurfactantProtein A \\
\hline
\end{tabular}




\begin{tabular}{ll} 
SFTPB & SurfactantProtein B \\
SFTPC & SurfactantProtein C \\
\hline SFTPD & SurfactantProtein D \\
\hline SOX2 & SRY (Sex Determining Region Y)-box 2 \\
\hline TBP & TATA Box Binding Protein \\
\hline TP53BP1 & Tumor Protein P53 Binding Protein 1 \\
TP63 & Tumor Protein p63 \\
\hline$\mu \mathrm{m}$ & Micrometer
\end{tabular}

\section{Declarations}

\section{Ethics approval and consent to participate}

The use of the hESC line AND-2 and the experimental procedures of this study were approved by the ISCIII Ethics Committee (ref. no. CEI PI 10_2015-v2) and the National Committee of Guarantees for the Use and Donation of human Cells and Tissues (ref. no. 3452881 and 436351 1).

\section{Consent for publication}

Not applicable

\section{Availability of data and materials}

Please contact the corresponding author for data requests.

\section{Competing interests}

The authors have not conflict of interests to declare

\section{Funding}

This work was supported by the Grant PI19CIII/00003 from the Institute of Health Carlos III (ISCIII) to Alberto Zambrano.

\section{Authors' contributions}

EM-L performed and designed experiments, analyzed data. I C-H performed experiments. AZ performed and designed experiments, analyzed data, wrote paper and conceived the project. The authors read and approved the final manuscript.

\section{Acknowledgements}


We thank the histology facility (Manolín and Marta) of the ISCIII for technical help.

\section{References}

1. King, TE Jr, Pardo A, Selman M. Idiopathic pulmonary fibrosis. Lancet. 2011 Dec 3; 378(9807): p. 1949-61.

2. Hecker L, Logsdon NJ, Kurundkar D, Kurundkar A, Bernard K, Hock T, Meldrum E, Sanders YY, Thannickal VJ. Reversal of persistent fibrosis in aging by targeting Nox4-Nrf2 redox imbalance. ci Transl Med. 2014 Apr 9; 6(231): p. 231 ra47.

3. Lv XX, Wang XX, Li K, Wang ZY, Li Z, Lv Q, Fu XM, Hu ZW. Rupatadine protects against pulmonary fibrosis by attenuating PAF-mediated senescence in rodents. PLoS One. 2013 Jul 15; 8(7): p. e68631.

4. Shivshankar P, Brampton C, Miyasato S, Kasper M, Thannickal VJ, Le Saux CJ. Caveolin-1 deficiency protects from pulmonary fibrosis by modulating epithelial cell senescence in mice. Am J Respir Cell Mol Biol. 2012 Jul; 47(1): p. 28-36.

5. Ding N, Yu RT, Subramaniam N, Sherman MH, Wilson C, Rao R, Leblanc M, Coulter S, He M, Scott C, Lau SL, Atkins AR, Barish GD, Gunton JE, Liddle C, Downes M, Evans RM. A vitamin D receptor/SMAD genomic circuit gates hepatic fibrotic response. Cell. 2013 Apr 25; 153(3): p. 601-13.

6. Ito I, Waku T, Aoki M, Abe R, Nagai Y, Watanabe T, Nakajima Y, Ohkido I, Yokoyama K, Miyachi H, Shimizu T, Murayama A, Kishimoto H, Nagasawa K, Yanagisawa J. A nonclassical vitamin D receptor pathway suppresses renal fibrosis. J Clin Invest. 2013 Nov; 123(11): p. 4579-94.

7. Meredith A, Boroomand S, Carthy J, Luo Z, McManus B. 1,25 Dihydroxyvitamin D3 Inhibits TGF $\beta 1$ Mediated Primary Human Cardiac Myofibroblast Activation. PLoS One. 2015 Jun 10; 10(6): p. e0128655.

8. Zhang Z, Yu X, Fang X, Liang A, Yu Z, Gu P, Zeng Y, He J, Zhu H, Li S, Fan D, Han F, Zhang L, Yi X. Preventive effects of vitamin $D$ treatment on bleomycin-induced pulmonary fibrosis. Sci Rep. 2015 Dec 2; 5: p. 17638.

9. Tan ZX, Chen YH, Xu S, Qin HY, Zhang C, Zhao H, Xu DX. Calcitriol inhibits bleomycin-induced early pulmonary inflammatory response and epithelial-mesenchymal transition in mice.. Toxicol Lett. 2016 Jan 5; 240(1): p. 161-71.

10. Guijarro T, Magro-Lopez E, Manso J, Garcia-Martinez R, Fernandez-Aceñero MJ, Liste I, Zambrano A. Detrimental pro-senescence effects of vitamin D on lung fibrosis.. Mol Med.. 2018 Dec 19; 24(1): p. 64.

11. Wyman C, Kanaar R. DNA double-strand break repair: all's well that ends well. Rev Genet.. 2006; 40: p. 363-83.

12. Campisi J, d'Adda di Fagagna F.. Cellular senescence: when bad things happen to good cells. Nat Rev Mol Cell Biol. 2007 Sep; 8(9): p. 729-40.

13. Aoshiba K, Tsuji T, Kameyama S, Itoh M, Semba S, Yamaguchi K, Nakamura H.. Senescenceassociated secretory phenotype in a mouse model of bleomycin-induced lung injury.. Exp Toxicol 
Pathol. 2013 Nov; 65(7-8): p. 1053-62..

14. Aoshiba K, Zhou F, Tsuji T, Nagai A.. DNA damage as a molecular link in the pathogenesis of COPD in smokers. Eur Respir J. 2012 Jun; 39(6): p. 1368-76.

15. Chilosi M, Carloni A, Rossi A, Poletti V.. Premature lung aging and cellular senescence in the pathogenesis of idiopathic pulmonary fibrosis and COPD/emphysema.. Transl Res. 2013; 162(3): p. 156-173.

16. Kuwano K, Araya J, Hara H, Minagawa S, Takasaka N, Ito S, Kobayashi K, Nakayama K. Cellular senescence and autophagy in the pathogenesis of chronic obstructive pulmonary disease (COPD) and idiopathic pulmonary fibrosis (IPF). Respir Investig.. 2016 Nov; 54(6): p. 397-406..

17. Leyssens C, Verlinden L, Verstuyf A. The future of vitamin D analogs. Front Physiol.. 2014 Apr 3; 5: p. 122.

18. Slatopolsky E, Finch J, Brown A.. New vitamin D analogs. Kidney Int Suppl. 2003 Jun; 85: p. S83-7..

19. Rogakou EP, Boon C, Redon C, Bonner WM.. Megabase chromatin domains involved in DNA doublestrand breaks in vivo. J Cell Biol.. 1999 Sep 6; 146(5): p. 905-16.

20. Schultz LB, Chehab NH, Malikzay A, Halazonetis TD. p53 binding protein 1 (53BP1) is an early participant in the cellular response to DNA double-strand breaks. J Cell Biol.. 2000 Dec 25; 151(7): p. 1381-90..

21. Abraham RT. Checkpoint signalling: focusing on 53BP1. Nat Cell Biol.. 2002 Dec 4; 12: p. E277-9.

22. Zambrano A, García-Carpizo V, Gallardo ME, Villamuera R, Gómez-Ferrería MA, Pascual A, Buisine N, Sachs LM, Garesse R, Aranda A.. The thyroid hormone receptor $\beta$ induces DNA damage and premature senescence.. J Cell Biol.. 2014 Jan 6; 204(1): p. 129-46.

23. Ward IM, Minn K, Jorda KG, Chen J.. Accumulation of checkpoint protein 53BP1 at DNA breaks involves its binding to phosphorylated histone H2AX.. J Biol Chem. 2003 May 30; 278(22): p. 1957982.

24. Magro-Lopez E, Guijarro T, Martinez I, Martin-Vicente M, Liste I, Zambrano A. A Two-Dimensional Human Minilung System (Model) for Respiratory Syncytial Virus Infections.. Viruses. 2017 Dec 10; 9(12): p. 379.

25. Magro-Lopez E, Palmer C, Manso J, Liste I, Zambrano A.. Effects of lung and airway epithelial maturation cocktail on the structure of lung bud organoids.. Stem Cell Res Ther. 2018 Jul 11; 9(1): p. 186.

26. Huang SX, Green MD, de Carvalho AT, Mumau M, Chen YW, D'Souza SL, Snoeck HW.. The in vitro generation of lung and airway progenitor cells from human pluripotent stem cells. Nat Protoc. 2015 Mar; 10(3): p. 413-25.

27. Huang SX, Islam MN, O'Neill J, Hu Z, Yang YG, Chen YW, Mumau M, Green MD, Vunjak-Novakovic G, Bhattacharya J, Snoeck HW.. Efficient generation of lung and airway epithelial cells from human pluripotent stem cells.. Nat Biotechnol. 2014 Jan; 32(1): p. 84-91.. 
28. Chen YW, Huang SX, de Carvalho ALRT, Ho SH, Islam MN, Volpi S, Notarangelo LD, Ciancanelli M, Casanova JL, Bhattacharya J, Liang AF, Palermo LM, Porotto M, Moscona A, Snoeck HW.. A threedimensional model of human lung development and disease from pluripotent stem cells.. Nat Cell Biol. 2017 May; 19(5): p. 542-549..

29. Martínez I, García-Carpizo V, Guijarro T, García-Gomez A, Navarro D, Aranda A, Zambrano A.. nduction of DNA double-strand breaks and cellular senescence by human respiratory syncytial virus.. Virulence. 2016 May 18; 7(4): p. 427-42..

\section{Figures}


Figure 1 Magro-Lopez et al.

A

\section{Bleomycin}
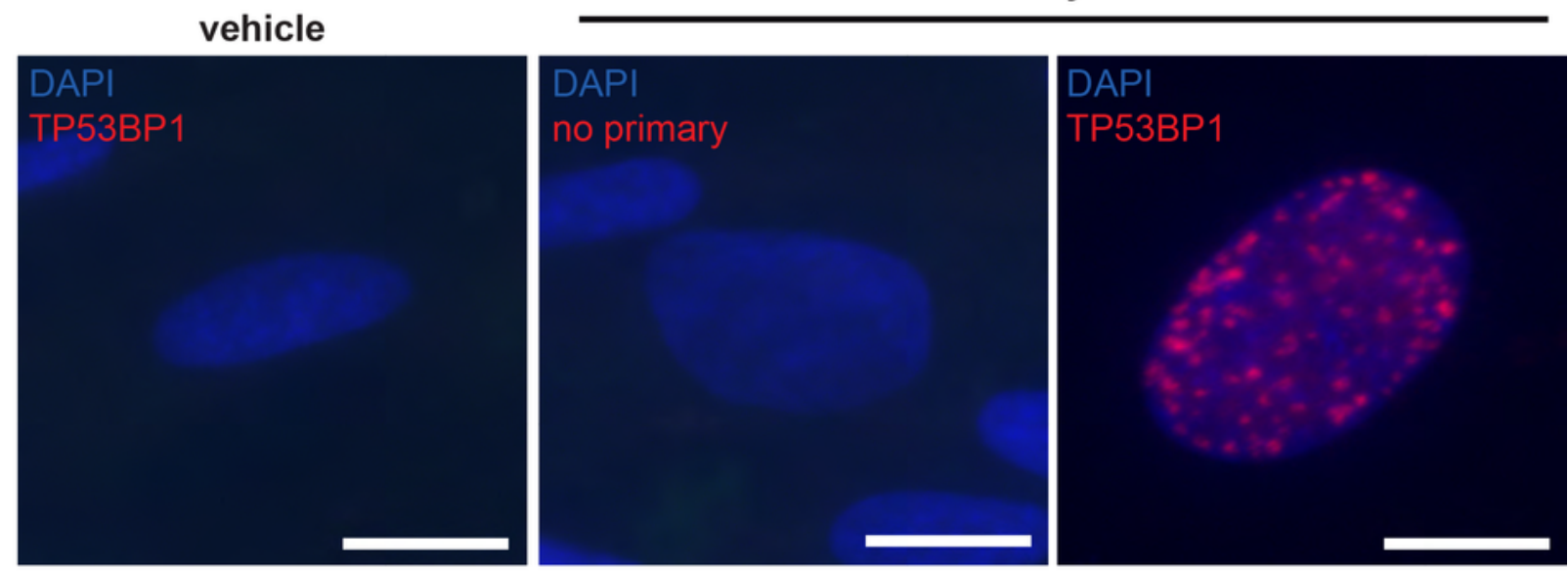

B

Bleomycin + veh.

Bleomycin + Vit D
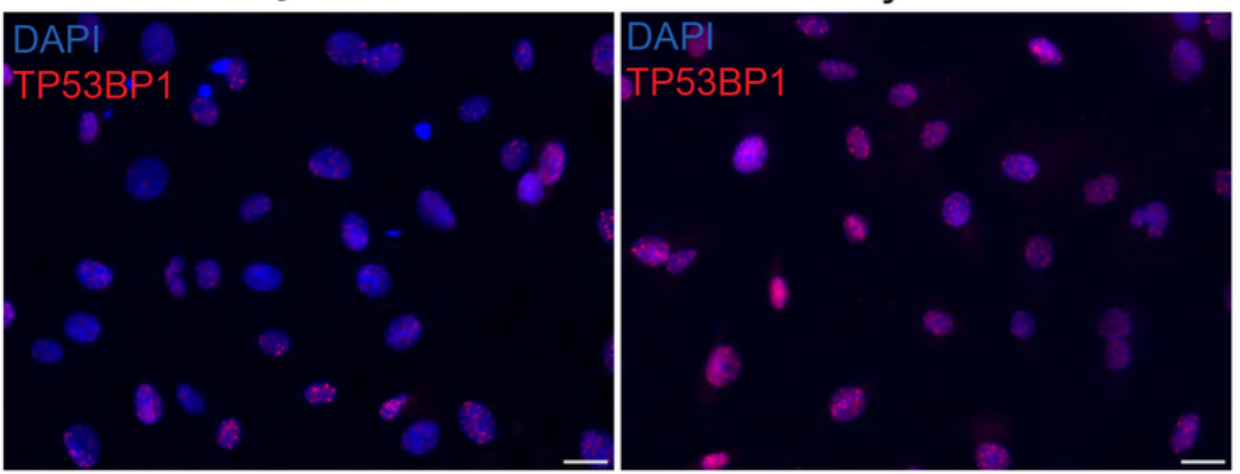

C

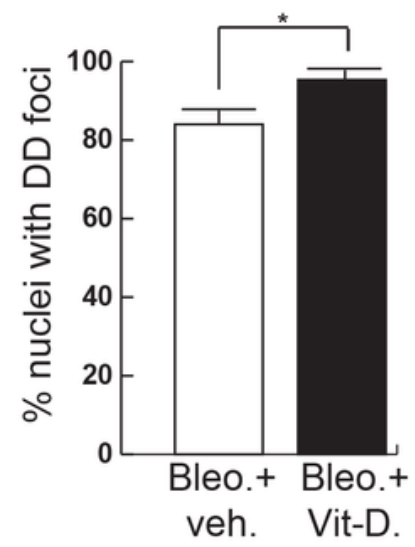

D

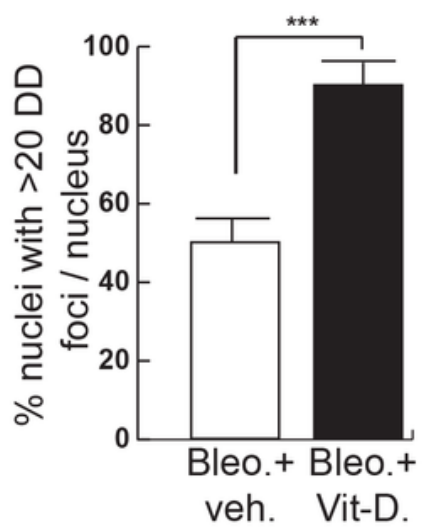

\section{Figure 1}

Effects of bleomycin and vitamin D in A549 cells. A. A549 cells were treated with $25 \mu \mathrm{g} / \mathrm{mL}$ of bleomycin for $48 \mathrm{~h}$ and then processed for indirect immunofluorescence to detect DNA damage foci containing TP53BP1 (red dots), a reliable marker of DNA double-strand breaks (DSBs). veh: Bleomycin vehicle (PBS). No primary: negative control of the immunofluorescence assay consisting of the absence of primary antibody. Scale bar: 5 um. B. Expression of DSBs [TP53BP1 foci (red dots)] induced by vitamin D in the 
presence of bleomycin. A549 cells were pretreated with $5 \mathrm{nmol} / \mathrm{L}$ vitamin $\mathrm{D}$ for $2 \mathrm{~h}$, subjected to a bleomycin shock $(12 \mu \mathrm{g} / \mathrm{mL}$ for $6 \mathrm{~h})$ and then treated with $5 \mathrm{nmol} / \mathrm{L}$ vitamin $D$ or its vehicle.

Representative micrographs taken at $48 \mathrm{~h}$ post-shock are shown. Scale bar: $20 \mu \mathrm{m}$. C-D. Quantification of damaged cell: \% of nuclei with TP53BP1 foci (C) or \% of severely damaged cells [more than 20 TP53BP1 foci per nucleus (D)]. Data from three experiments are represented; more than 150 cells per condition were analyzed $(P<0,001)$.

Figure 2 Magro-Lopez et al.

A

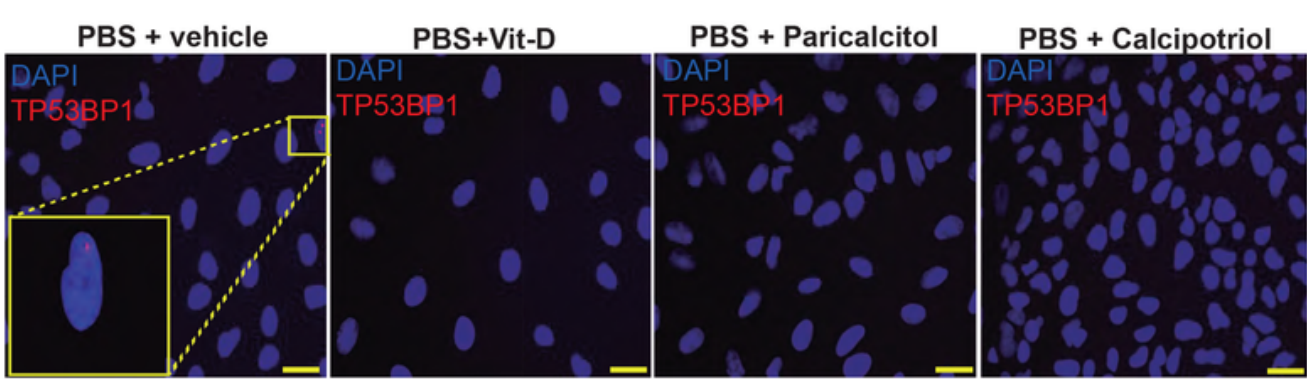

B

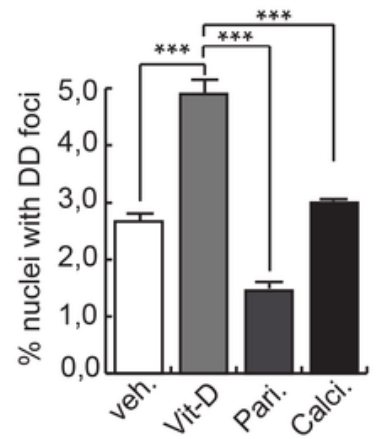

C

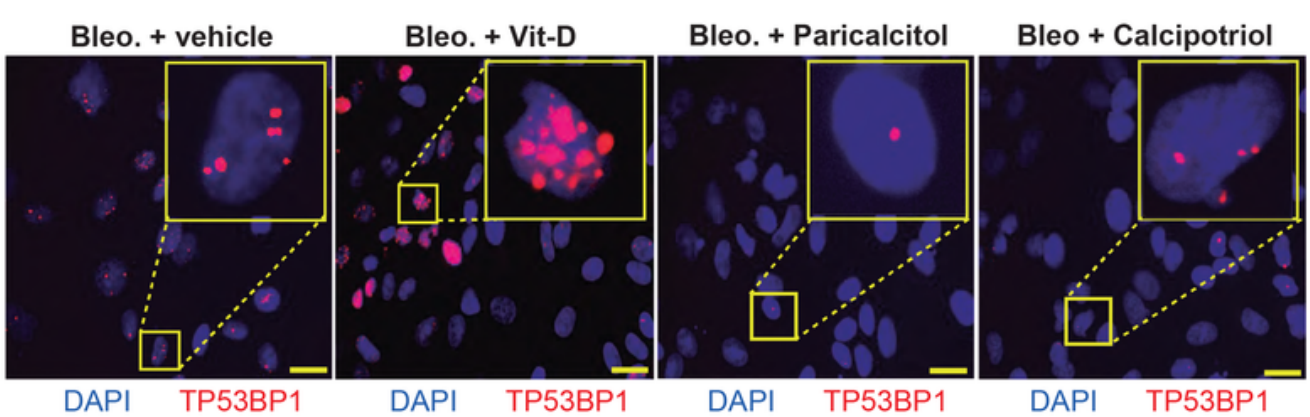

D

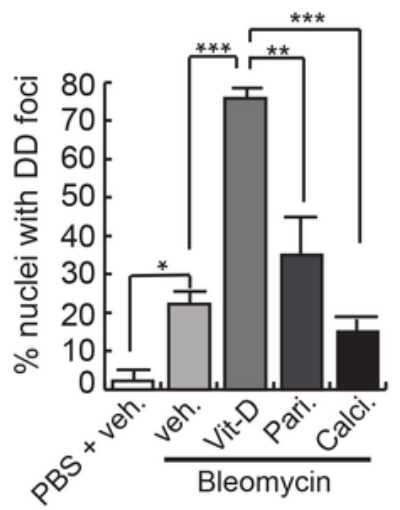

Figure 2 
Effects of vitamin D and two hypocalcemic analogs in the expression of DNA damage induced by bleomycin in A549 cells. A. Basal expression of DSBs (TP53BP1 foci (red dots)) induced by vitamin D and the analogs paricalcitol and calcipotriol in the absence of bleomycin. A549 cells were treated with 50 $\mathrm{nmol} / \mathrm{L}$ vitamin $\mathrm{D}$ (or the corresponding analog) for $48 \mathrm{~h}$ and then subjected to immunofluorescence to detect DD foci. Representative micrographs are shown. PBS is the bleomycin vehicle; vehicle: vitamin D or analogs vehicle; scale bar: $100 \mu \mathrm{m}$. B. Quantification of damaged cells (nuclei with TP53BP1 foci). Data from three experiments are represented; more than 150 cells per condition were analyzed. ANOVA $P<0,001$. C. Expression of TP53BP1 foci (red dots) in cultures of $A 549$ cells pretreated with $50 \mathrm{nmol} / \mathrm{L}$ vitamin $D$, analogs or its vehicle for $2 \mathrm{~h}$ and subjected to a bleomycin shock $(12 \mu \mathrm{g} / \mathrm{mL})$ for $6 \mathrm{~h}$. After that, the cultures were treated with $50 \mathrm{nmol} / \mathrm{L}$ vitamin $\mathrm{D}$ and the analogs paricalcitol and calcipotriol (or vehicle) for $48 \mathrm{~h}$. Representative micrographs taken at $48 \mathrm{~h}$ post-shock are shown. Scale bar: $100 \mu \mathrm{m}$. D. Quantification of damaged cells; veh: vitamin D or analogs vehicle. Data from three experiments are represented; more than 150 cells per condition were analyzed; ANOVA $P<0,001$. The results presented in the figures are means \pm SEM. Significance of the analysis is indicated as, $*: P<0.05, * \star: P<0.01, * \star *$ : $p<0.001$. 
A
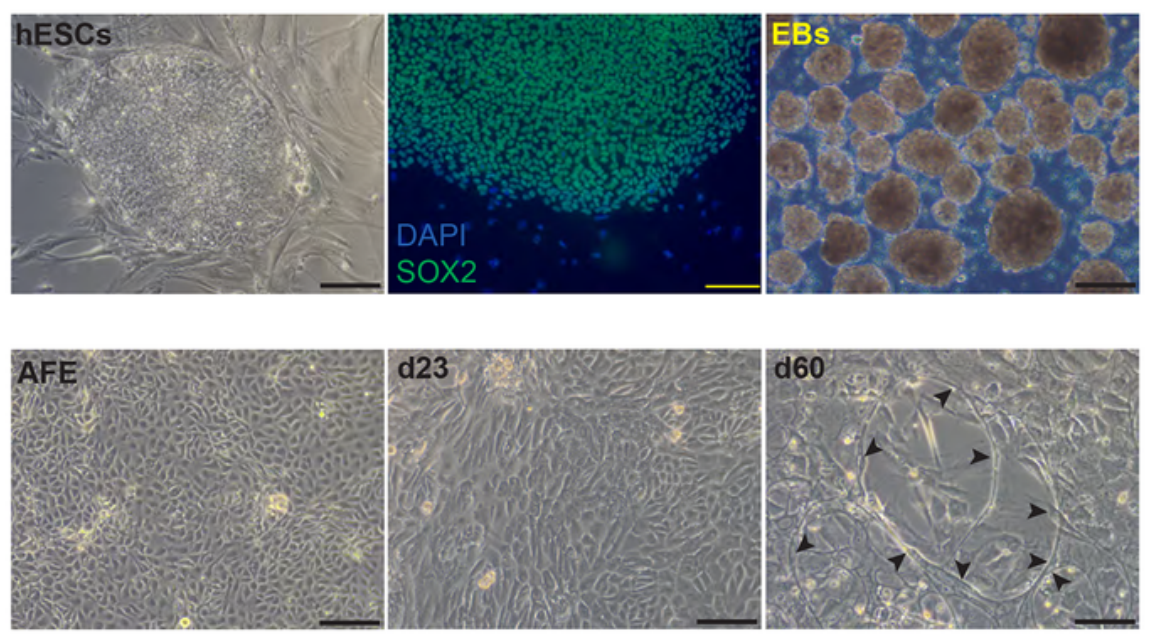

B

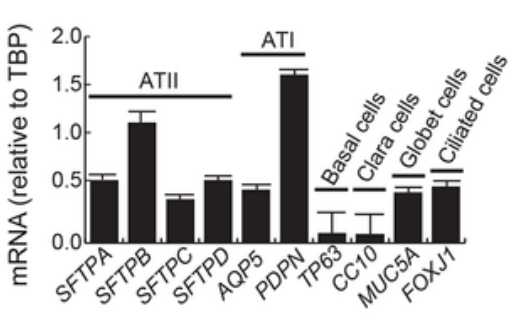

C

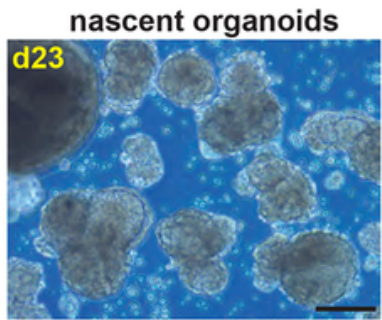

D

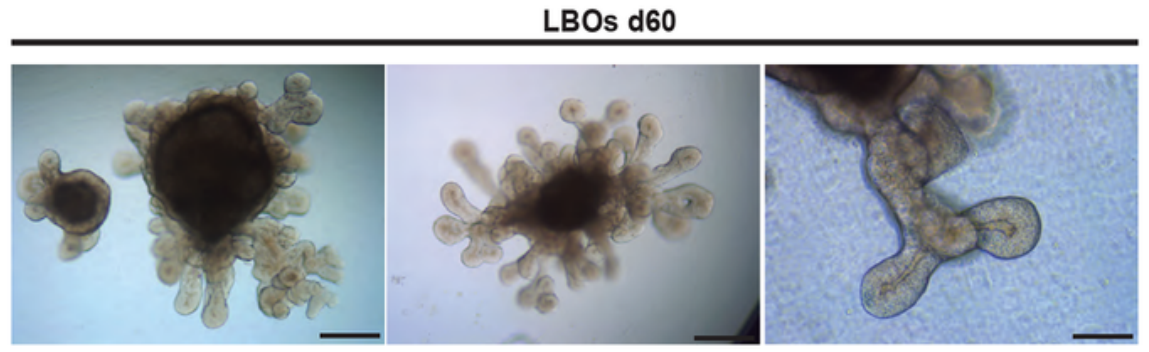

E

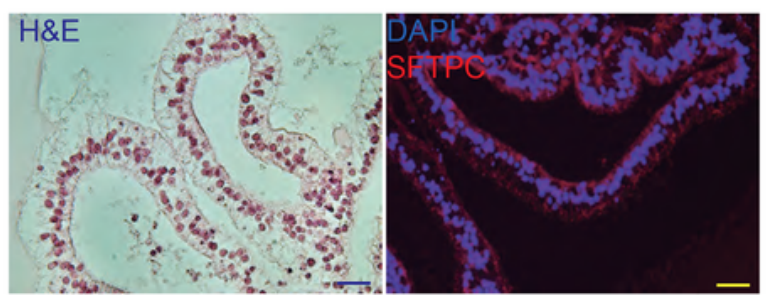

\section{Figure 3}

Representative micrographs of the sequential differentiation processes and expression markers. (A) left upper micrograph: AND-2 colony growing along with feeder cells [inactivated MEFs (iMEFs)]; scale bar: $100 \mu \mathrm{m}$ ); central upper micrograph: expression of SOX2 (SRY (Sex Determining Region Y)-box 2) in an undifferentiated colony of AND-2; scale bar: $100 \mu \mathrm{m}$ ). Right upper micrograph: Representative micrograph of EBs (embryoid bodies). Bottom panels: AFE (anterior foregut endoderm) and representative 
micrographs of cultures at day 23 of differentiation (lung progenitors) and at day 60 (differentiated lung and airway cells): Black arrowheads signal cells with a typical flat and crescent shape morphology denoting alveolar type I cells (ATI cells); scale bar: $100 \mu \mathrm{m}$. B. Levels of expression [relative to TBP (TATA Box Binding Protein)] of lung and airway epithelial cells markers at day $60(n=3 ;>4$ organoids per condition were used). C. Representative micrograph of nascent organoids growing in suspension at day 23. D. Representative micrograph of LBOs at day 50 embedded in MatrigelTM sandwiches; scale bar: 100 $\mu \mathrm{m}$ and $50 \mu \mathrm{m}$ (micrograph on the right). E. Micrograph on the left: Histochemical analysis of LBO sections (H\&E staining); representative micrograph of an immunohistochemical staining of LBO sections (micrographon the right) with a SFTP-C antibody. Scale bar: $100 \mu \mathrm{m}$. 
A

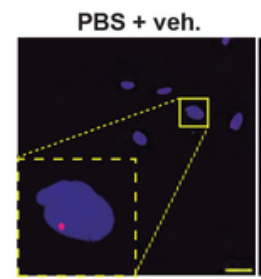

DAPI TP53BP1

C

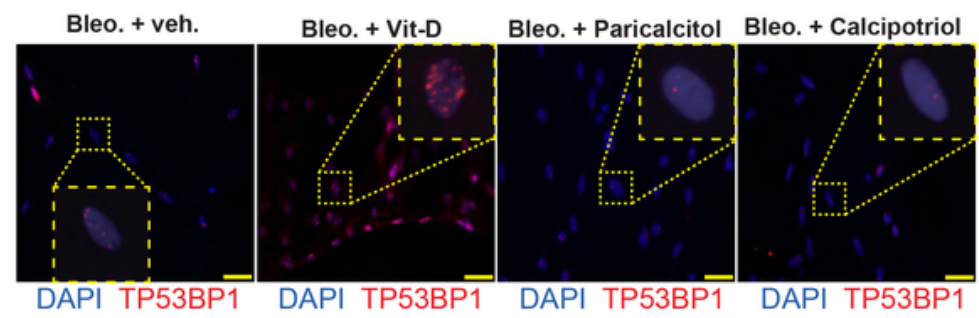

E

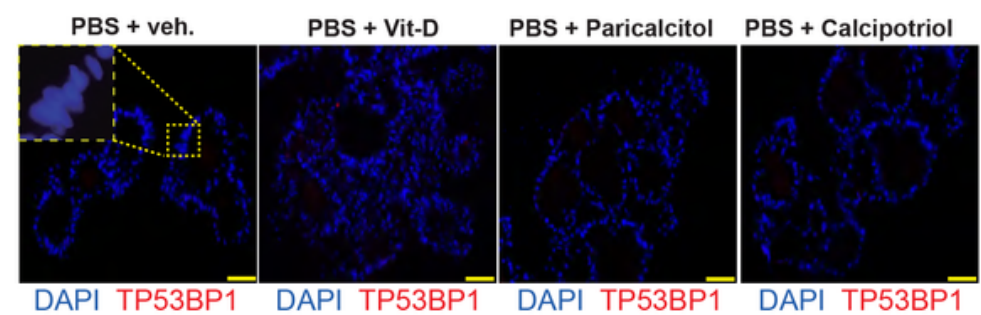

G

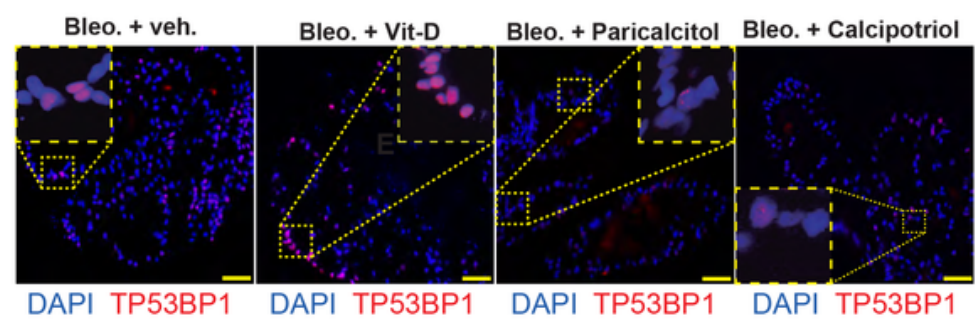

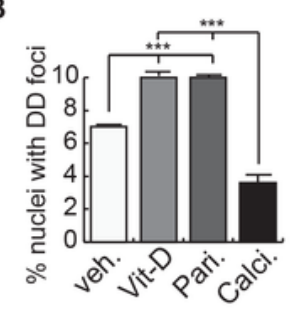

D

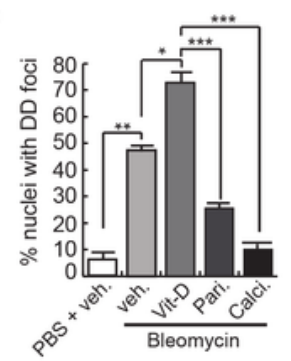

$\mathbf{F}$

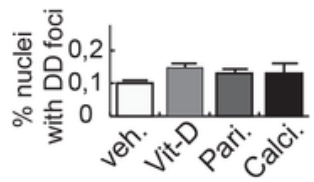

H

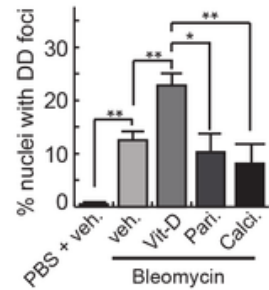

I

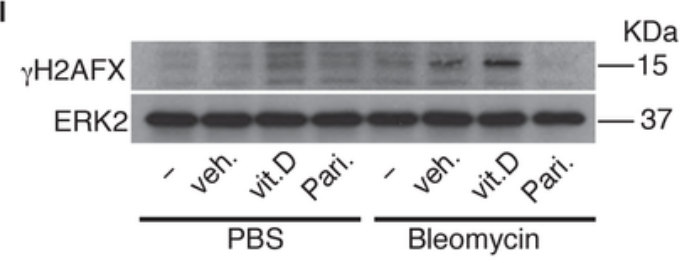

J
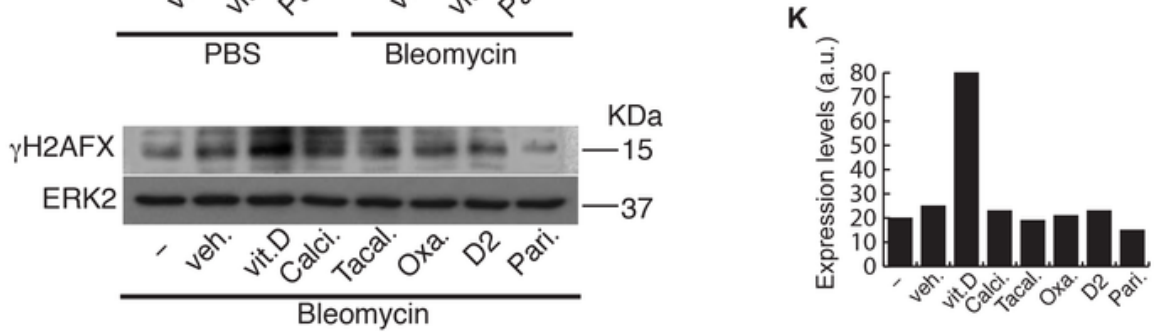

\section{Figure 4}

Effects of vitamin D and hypocalcemic analogs in the expression of DNA damage induced by bleomycin in the minilungs generated from hESCs. A. Basal expression of DNA damage (TP53BP1 foci (red dots)) induced by vitamin $D$ and the analogs paricalcitol and calcipotriol in the absence of bleomycin. 2D minilungs were treated with $50 \mathrm{nmol} / \mathrm{L}$ vitamin $\mathrm{D}$ (or the corresponding analog) for $72 \mathrm{~h}$ and then subjected to immunofluorescence to detect DD foci. Representative micrographs are shown. PBS is the 
bleomycin vehicle; veh.: vitamin D or analogs vehicle; scale bar: $100 \mu \mathrm{m}$. B. Quantification of damaged cells (nuclei harboring TP53BP1 foci) corresponding to conditions $A ;(n=3 ;>150$ cells were analyzed; ANOVA P<0,001). C. Expression of TP53BP1 foci (red dots) in 2D minilungs cells pretreated with 50 $\mathrm{nmol} / \mathrm{L}$ vitamin $\mathrm{D}$, analogs or its vehicle for $2 \mathrm{~h}$ and then with bleomycin $(12,5 \mu \mathrm{g} / \mathrm{mL})$, vitamin $\mathrm{D}$ or analogs $(50 \mathrm{nmol} / \mathrm{L})$ for $72 \mathrm{~h}$. After that, the cultures were processed for indirect immunofluorescence to detect DNA damage foci containing TP53BP1 (red dots); representative micrographs are shown. Scale bar: $100 \mu \mathrm{m}$. D. Quantification of damaged cells corresponding to conditions C. veh: vitamin D or analogs vehicle; $(n=3 ;>150$ cells were analyzed; ANOVA $P<0,001)$. E. Basal expression of DNA damage in 3D minilungs (LBOs): TP53BP1 foci (red dots) induced by vitamin D and the analogs paricalcitol and calcipotriol in the absence of bleomycin. 3D minilungs (LBOs) were treated with $50 \mathrm{nmol} / \mathrm{L}$ vitamin D (or the corresponding analog) for $72 \mathrm{~h}$ and then subjected to immunofluorescence to detect DD foci. Representative micrographs are shown. PBS is the bleomycin vehicle; veh.: vitamin D or analogs vehicle; scale bar: $100 \mu \mathrm{m}$. F. Quantification of damaged cells corresponding to condition $\mathrm{E}$ (nuclei harboring TP53BP1 foci); ( $n=3$; >4 organoids per condition were used and >150 cells were analyzed; ANOVA $P>0,05)$. G. Expression of TP53BP1 foci (red dots) in 3D minilungs (LBOs) cells pretreated with $50 \mathrm{nmol} / \mathrm{L}$ vitamin $\mathrm{D}$, analogs or its vehicle for $2 \mathrm{~h}$ and then with bleomycin $(25 \mu \mathrm{g} / \mathrm{mL})$, vitamin $\mathrm{D}$ or analogs (50 $\mathrm{nmol} / \mathrm{L}$ ) for $72 \mathrm{~h}$. After that, the cultures were processed for indirect immunofluorescence to detect DNA damage foci containing TP53BP1 (red dots); representative micrographs are shown. Scale bar: 100 $\mathrm{mm}$. H. Quantification of damaged cells corresponding to condition G (nuclei harboring TP53BP1 foci); $(n=3$; >4 organoids per condition were used and $>150$ cells were analyzed; ANOVA $P<0,001)$. The results presented in the figures are means \pm SEM. Significance of the analysis is indicated as, $*$ : $P<0.05, * *$ : $P<0.01, \star \star *$ : $\mathrm{p}<0.001$. I. Detection of $\mathrm{YH} 2 \mathrm{AFX}$ in A549 cell extracts. Cells were pretreated with $50 \mathrm{nmol} / \mathrm{L}$ vitamin D for $2 \mathrm{~h}$, subjected to a bleomycin shock $(12 \mu \mathrm{g} / \mathrm{mL}$ for $6 \mathrm{~h})$ and then treated with $50 \mathrm{nmol} / \mathrm{L}$ vitamin $\mathrm{D}$ or its vehicle. Cell extracts were obtained at $48 \mathrm{~h}$ post-shock; Pari: paricalcitol; ERK2 was used as loading control. KDa: kilodaltons. J. Detection of yH2AFX in A549 cell extracts. Cells were treated as in J. Cell extracts were obtained at $48 \mathrm{~h}$ post-shock; Calci: calcipotriol; Tacal: tacalcitol; Oxa.: 22-oxacalcitriol; D2: vitamin D2; Pari: paricalcitol; ERK2 was used as loading control. KDa: kilodaltons. K: densitometry analysis of western J; a.u: arbitrary units. 